\title{
Infuboy oder die kurze Geschichte einer Innovation
}

Bruno Krapf

Korrespondenz:

Prof. Dr. phil. Bruno Krapf Säntisstrasse 38

CH-8311 Brütten

bruno.krapf[at]uzh.ch
Seit kurzem sieht man in einigen Spitälern Personen mit Infusionen ausgerüstet munter daherkommen. Sie tragen gerade ein Tablett an ihren Tisch im Spitalcafé oder sie wählen am Kiosk eine Ansichtskarte aus. Da kommt jemand mit dem Rollator daher oder weiss sich mit zwei Stöcken sicher auf den Beinen. Alle haben beide Hände frei und immer ist die Infusion dabei. So etwas gab es lange nicht. Wer hat den tragbaren Infusionsflaschenhalter erfunden?

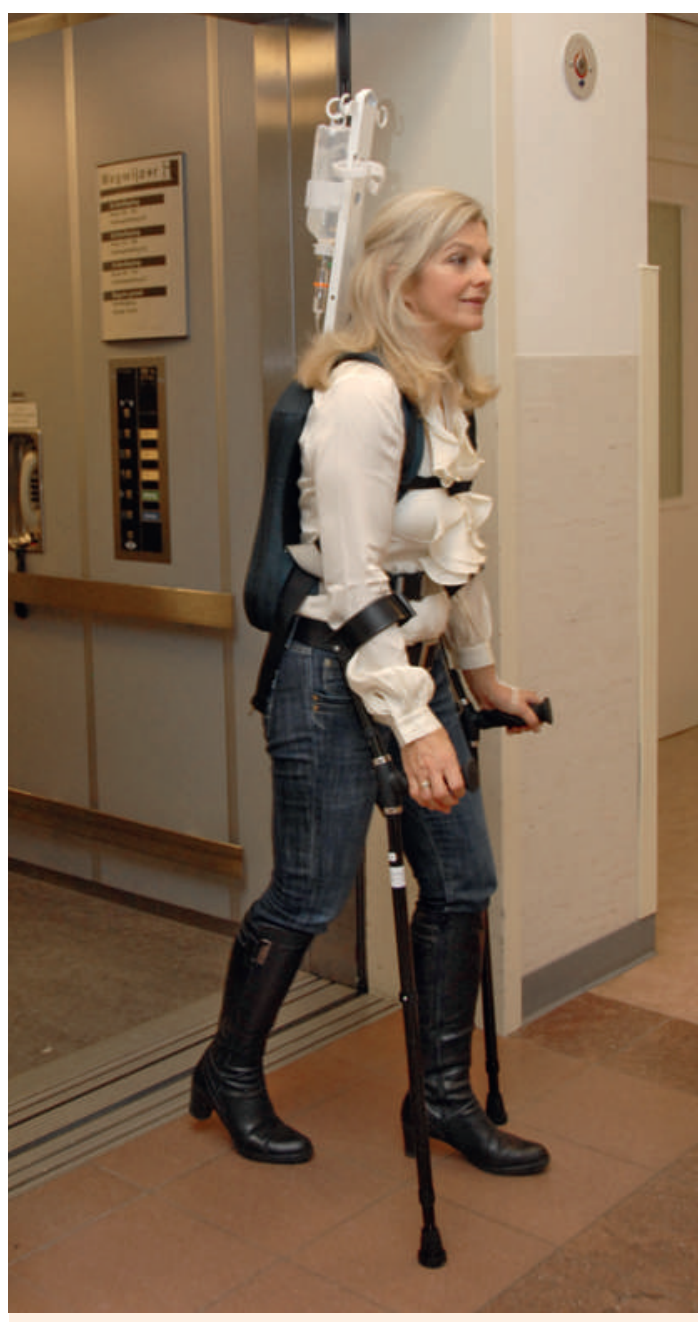

Dank Infuboy kommt man auch mit Krücken leichter voran.

\section{Entstehungs- geschichte des Infuboy}

Nach zwei schwierigen Operationen und längerem Spitalaufenthalt kam ich in die Reha-Klinik. Drei Wochen, alle vier Stunden eine Infusion. Die Klinik liegt an einem steilen Hang mit schöner Aussicht auf den See. Für mich war es unmöglich, mit dem Infusionsständer im Garten zu wandern. Als einziger

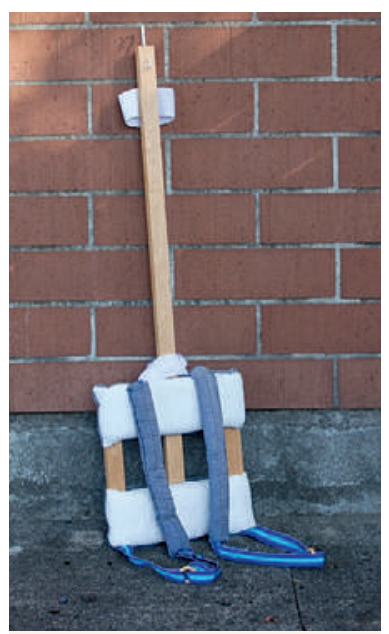

Das erste Modell. Aufenthaltsort im Freien blieb mir der Balkon. Meine Frau und ich überlegten uns, wie Bergbauern sich früher im steilen Gelände verhielten, wenn sie etwas transportieren mussten, und wir erinnerten uns an das hölzerne Traggestell, das die Bauern auf dem Rücken trugen, das Reff.

Meine Frau konstruierte noch am gleichen Tag ein Gestell aus Dachlatten, in der Mitte mit einem etwas längeren Stab mit Haken für die Infusionsflaschen. Das Traggestell und die Tragriemen waren gepolstert. Der erste Infuboy war gebaut.

Mit dem Infuboy am Rücken lernte ich schnell wieder Treppen steigen und mich auf unebenem Gelände zu bewegen. Schon bald überquerten wir die Strasse und genossen das Abendessen unten im Seerestaurant. Es war fast ein wenig wie Ferien.

Den technischen und medizinischen Perfektionierungen aufgrund von Tests und Tragversuchen folgten die CE-Zertifizierung, die Patentanmeldung und schliesslich die industrielle Produktion. Die Patientinnen und Patienten, die unterdessen den Infuboy benützen konnten, waren begeistert. Sie waren der Ansicht, die Bewegungssicherheit fördere in vielen Fällen den Heilungsprozess, stärke das Selbstvertrauen und die Zuversicht. Ein ganz normaler Bewegungsablauf wurde wieder eingeübt.

Weitere Informationen: www.infuboy.com 